\title{
Optimalisasi Umur Pemakaian AC Melalui Sistem Informasi Reminder Perawatan
}

\author{
Aries Setiawan $^{* 1}$, Sasono Wibowo ${ }^{2}$, Ida Farida ${ }^{3}$ \\ ${ }^{1,2}$ Program Studi Teknik Informatika, Universitas Dian Nuswantoro \\ ${ }^{3}$ Program Studi Manajemen, Universitas Dian Nuswantoro \\ email: arissetya_005@dsn.dinus.ac.id*1, sasono.wibowo@dsn.dinus.ac.id ${ }^{2}$, \\ ida.farida@dsn.dinus.ac.id ${ }^{3}$
}

(Received: 29 April 2021/ Accepted: 10 Juni 2021 / Published Online: 20 Juni 2021)

\begin{abstract}
Abstrak
Belum adanya penjadwalan periodik perawatan Air Conditioner (AC) yang berpangkal dari minimnya pencatatan pada kartu perawatan dan buku perawatan sehingga mengakibatkan banyaknya kerusakan AC yang merambat pada satu komponen ke komponen hingga akhirnya AC tidak bisa berfungsi total. Diperlukan sebuah sistem untuk memberikan informasi yang akan mengingatkan waktu perawatan sebagai langkah awal optimalisasi umur pemakaian AC. Tujuan penelitian ini adalah membuat sistem informasi reminder perawatan, agar AC yang digunakan dirawat sesuai jadwal yang sudah ditentukan. Metode yang digunakan untuk membangun sistem ini adalah waterfall dengan lima langkah, yakni: analisis, desain, implementasi, dan testing. Untuk menguji sistem ini menggunakan black box testing, dengan menguji setiap bagian dari masing-masing sistem. Hasil temuan kami adalah menghasilkan sistem reminder perawatan yang sesuai dengan standar. Hasil pengujian menunjukkan bahwa semua komponen pada sistem berfungsi dengan baik, sehingga pengguna semakin mudah dalam mengetahui AC mana saja yang perlu perawatan. Dengan adanya sistem ini, dapat memaksimalkan fungsi perawatan untuk mengoptimalkan umur pemakaian.
\end{abstract}

Kata kunci: AC, Optimalisasi, Reminder, Sistem Informasi,

\begin{abstract}
There is no periodic scheduling of Air Conditioner (AC) maintenance, which stems from the lack of recording on the maintenance card and maintenance book, resulting in a lot of AC damage that propagates from one component to component until finally the AC cannot function completely. A system is needed to provide information that will remind the time of maintenance as the first step in optimizing the life of the air conditioner. The purpose of this study is to build an information system of maintenance-reminder, so that the air conditioner used is maintained according to a predetermined schedule. The method used to build this system is a waterfall with five steps, namely: analysis, design, implementation, and testing. To Test the system that has been made, in this study using black boxtesting by checking every part of each system. Our findings are to produce a standardized maintenance reminder system. The test results show that all components in the system are functioning properly, so it is easier for users to know which air conditioners need maintenance. With this system, it can maximize the maintenance function to optimize service life.
\end{abstract}

Keywords: AC, Optimization, Reminder, Information System

\section{PENDAHULUAN}

Hampir semua hunian baik itu rumah tinggal, kantor, maupun tempat yang menjadi bermukimnya manusia tidak terlepas dari kebutuhan kenyamanan tinggal. Air Conditioner (AC) merupakan prasarana pendukung yang seiring dengan kondisi iklim menjadikan alih fungsinya sebagai kebutuhan pokok. Jumlah produksi AC juga meningkat seperti yang terjadi pada produsen panasonic yakni dari lima juta unit ac menjadi sepuluh juta unit dalam kurun waktu 10 tahun (Nugroho, 2019). Sejumlah AC yang komponenya rusak diluar jadwal 
dikarenakan AC tersebut kurang dipelihara, sehingga fungsi dan keawetan pada AC tidak dapat berumur panjang (Suryanto, 2020).

Perawatan AC menjadi komponen utama dalam penentu umur pemakaian, selain itu aktivitas perawatan AC berfungsi sebagai langkah untuk memberikan kenyamanan bagi pengguna, berpengaruh juga dari sisi kesehatan. Saat ini kebutuhan akan AC menjadi sebuah kebutuhan pokok baik bagi bangunan dengan skala penggunaan yang tinggi seperti perkantoran, hotel, rumah sakit, pusat perbelanjaan, apartemen maupun bangunan dengan skala kecil seperti rumah tinggal. Agar fungsi AC tertjaga dan tahan lama, hal penting yang harus diperhatikan adalah selalu memelihara komponen yang ada pada AC tersebut, serta selalu dibuatkan jadwal untuk dilakukannya perawatan atau maintenance agar kegiatan perawan tersebut dapat terlaksana sesuai jadwal yang telah ditetapkan.

Macam-macam kesalahan yang sering kita lakukan atau lalai dalam memperhatikan penggunaan $\mathrm{AC}$ adalah terjadinya penurunan efisiensi, peningkatan konsumsi energi, dan peningkatan biaya perawatan (Trivedi, Bhola, Talegaonkar, Gaur, \& Sharma, 2019). Komponen AC harus mendapat perawatan sesuai dengan jadwal yang telah ditenttukan baik mingguan maupun bulanan secara rutin.. Temuan yang ada yaitu banyaknya perawatan yang melebihi tanggal jatuh tempo perawatan, sehingga berdampak pada minimnya perawatan adalah kerusakan AC yang merambat pada satu komponen ke komponen hingga akhirnya AC tidak bisa berfungsi total (Gunawan, Setiawan, \& Legirian, 2017; Mishra, Chaulya, Prasad, Mandal, \& Banerjee, 2020; Putra \& Irawan, 2020).

Masalah yang terjadi diakibatkan belum adanya penjadwalan periodik perawatan AC, selain itu hal yang mungkin terlupakan adalah pencatatan di kartu perawatan dan minimnya pencatatan di buku perawatan. Perawatan perlu memperinci jenis pekerja dan banyak pekerja yang dibutuhkan (Margono, 2016). Perawatan sebagai konsep dari semua kegiatan yang berguna untuk menjaga kestabilan operasional alat seperti kondisi awal pembelian (Suryanto, 2020).

Sistem yang menghubungkan kebutuhan aktivitas transaksi periodik, pendukung operasi, strategi dan aktivitas manajemen organisasi untuk terciptanya hasil yang menjadi tujuan utama merupakan pengertian dari sistem operasi (Yuliandra \& Jaeba, 2017). Sistem informasi juga tidak terlepas dari database, dimana berperan untuk memanipulasi data (Melikhova, Rogachev, \& Skiter, 2019; Rusdin, Santoso, \& Darmadi, 2018; Ye, 2020)

Pada penelitian terkait mengenai Rancang Bangun Sistem Informasi Perawatan Mesin Produksi Keramik, disimpulkan bahwa dengan adanya sistem informasi perawatan memberikan solusi perawatan yang efektif serta membantu dalam pelaksanaan administrasi, serta dapat dalam pengelolaan data perawatan mesin berdasarkan work order (Nasution, 2019). Penelitian lain juga menyatakan bahwa, dengan adanya sistem informasi yang telah dibuat dapat memudahkan pengguna atau user dalam melakukan aktifitas mereka mengenai perawatan asset pada perusahaan mereka (Ridwan, Muhammad, \& Ramadhani, 2018). Selain itu, hasil penelitian lain juga menyatakan bahwa sistem informasi yang telah dibangun dapat mempermudah proses pengelolaan inventaris dan prasarana, proses laporan kerusakan, dan proses monitoring perawatan sarana dan prasarana.

Berdasrakan hasl tersebut di atas, pada sistem informasi perawatan diperlukan sebagai solusi dari masalah yang telah dijabarkan sebelumnya. Oleh karena itu, adapun tujuan yang dicapai pada penelitian ini adalah menciptakan sistem informasi perawatan AC yang juga dilengkapi reminder sebagai informasi AC di ruangan mana saja yang sudah jatuh tempo untuk dilakukan perawatan guna meningkatkan kehandalan fungsi AC sebagai pendingin ruangan dan memaksimalkan umur pemakaian. 


\section{METODE}

Menurut Muntohar, salah satu metode yang memiliki fungsi memberikan runtutan aktivitas mulai dari identifikasi masalah sampai dengan membangun sistem adalah metode waterfall, yang memiliki 4 tahapan (Muntohar, 2020). Tahap Analisis, pada tahap ini dilakukan analisis yang dilakukan pada penlitian ini adalah dengan melakukan pencarian masalah-masalah yang timbul di lapangan (Tabrani, 2017). Tahapan Desain, tahapan ini berupa rancangan sistem untuk pengembangan yang akan dibuat, meliputi context diagram, data flow diagram dan entity relationship diagram (Akbar \& Gunawan, 2020; Fadhlurrahman \& Capah, 2020; Purnia, Rifai, \& Rahmatullah, 2019). Selanjutnya Implementasi, tahap ini berkaitan dengan penerapan analisa ke tahapan rancangan system (Sasmito, 2017). Tahapan ini berisi tentang implementasi ke dalam aplikasi sistem reminder perawatan AC. Selanjutnya yang terakhir adalah tahapan testing. Tahapan ini berupa pengujian kesesuaian antara rancangan dengan sistem yang dihasilkan (Nere \& Buani, 2018). Pengujian dengan menggunakan blackbox, dengan menguji setiap bagian menu pada program/sistem yang telah dibuat (Hidayat \& Muttaqin, 2018; Munthe, Rambe, Pane, Irmayani, \& Nasution, 2020; Sholeh, Gisfas, \& Fauzi, 2021).

\section{HASIL DAN PEMBAHASAN Hasil}

Berdasarkan hasil analisis ataua pengamatan dilapangan, terdapat beberapa temuan yang menjadi dasar pengembangan sistem reminder perawatan yang terlihat pada tabel 1 sebagai berikut.

Tabel 1. Tabel Analisis Masalah

\begin{tabular}{cc}
\hline No & Temuan \\
\hline $\mathbf{1}$ & Banyak kartu perawatan yang tidak diisi sewaktu teknisi melakukan perawatan AC \\
& di setiap ruangan \\
$\mathbf{2}$ & Belum adanya pencatatan pada buku laporan perawatan \\
$\mathbf{3}$ & Banyaknya AC yang belum di servis sampai dengan tanggal jatuh tempo \\
& perawatan \\
$\mathbf{4}$ & Jarang dilakukan perawatan pada AC yang dirasa tidak bermasalah \\
$\mathbf{5}$ & Belum adanya laporan perawatan AC yang memuat semua AC yang sudah \\
& dilakukan perawatan ataupum belum \\
\hline
\end{tabular}

\section{Desain}

Desain sistem, dilakukan dengan beberapa diagram yaitu context diagram dan data flow diagram (Anisah, 2019). Gambar 1 merupakan context diagram, yang menggambarkan desain sistem secara umum, beberapa entitas yang terlibat yaitu teknisi, bagian sarana dan prasarana dan kepala teknisi. Teknisi memberikan dokumen daftar AC yang telah dilakukan perawatan ke sistem untuk selanjutnya teknisi menerima informasi berupa Reminder Daftar AC yang mendekati jatuh tempo perawatan AC dan Reminder Daftar AC yang melewati jatuh tempo perawatan AC. Selanjutnya context diagram diturunkan ke sub sistem dibawahnya yaitu data flow document seperti pada gambar 2.

Pada Data Flow Diagram Level 0 sistem diperinci lagi menjadi sub sistem pendataan, sub sistem perawatan dan sub sistem cetak laporan. Dengan penyimpanan berupa tabel ruang, tabel inventaris dan tabel perawatan. Pada sub sistem perawatan, aktivitas perawatan diolah dari tabel inventaris dan tabel perawatan untuk kemudian dihasilkan Reminder Daftar AC yang mendekati jatuh tempo perawatan AC dan Reminder Daftar AC yang melewati jatuh tempo perawatan $\mathrm{AC}$ dari sistem guna diserahkan ke entitas teknisi 


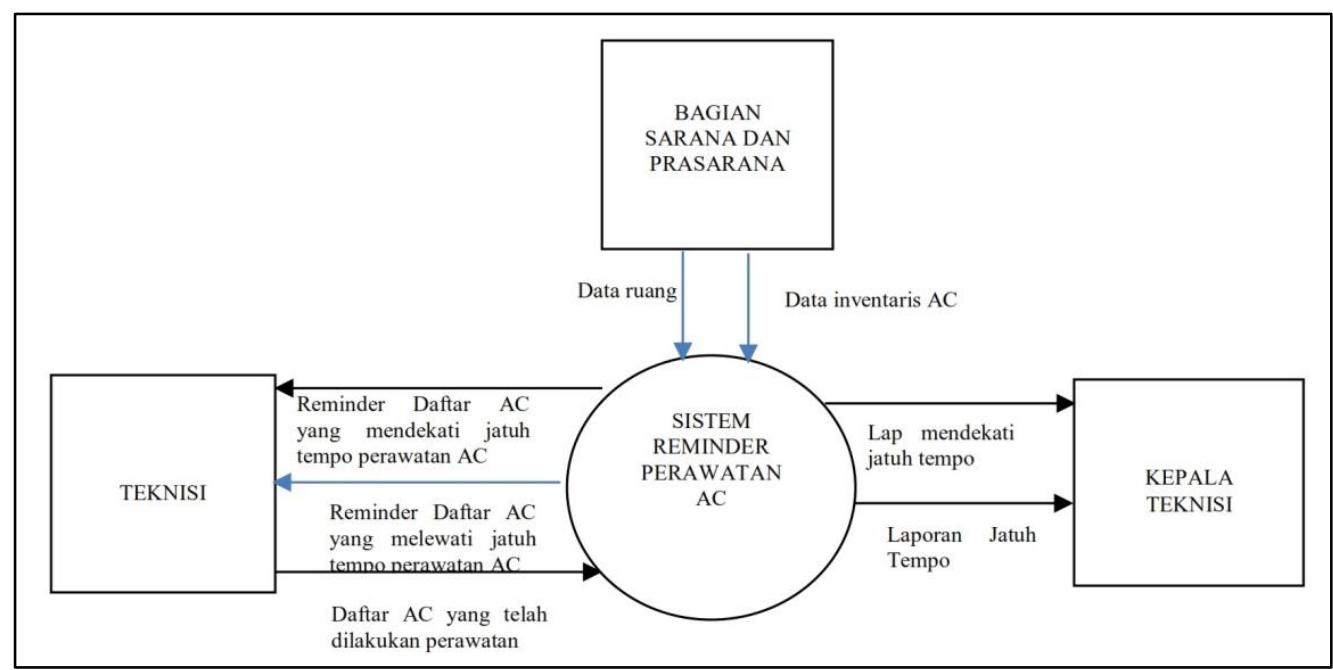

Gambar 1. Context Diagram

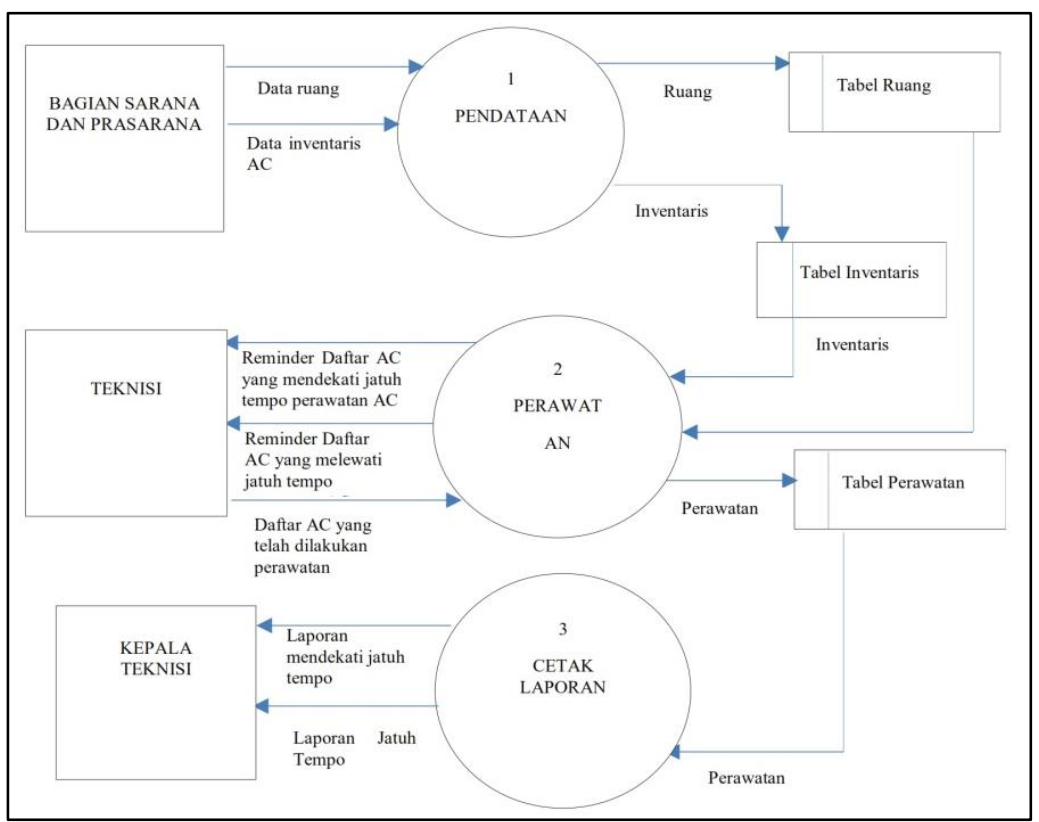

Gambar 2. Data Flow Diagram Level 0

Setelah dilakukan tahapan desain sistem, tahapan selanjutnya yang dilakukan adalah melakukan implementasi sistem, meliputi pendataan ruang, petuga, inventaris, perawatan serta beberapa laporan. Form pendataan ruang pada gambar 4 berfungsi untuk menambahkan data ruang, setelah data ruang diinputkan maka akan ada kotak kecil pada daftar inventaris AC yang ada pada tampilan utama aplikasi.

Form pendataan petugas pada gambar 5. berfungsi untuk menambahkan data petugas, untuk selanjutnya data petugas berfungsi untuk mengisikan pada pendataan perawatan tentang siapa petugas yang melakukan perawatan. Sementara itu gambar 6 dan 7 berisikan form pendataan inventaris dan perawatan. Dimana form ini berisi mengenai informasi nomor, kode, ukuran, tanggal beli, dan kondisi, serta tanggal jatuh tempo. Sementara itu pada gambar 8 berisi laporan inventaris yang mendekati jatuh tempo. Pada form ini berisi informasi mengenai merek AC, ukuran, tanggal beli, serta kode ruangan. 


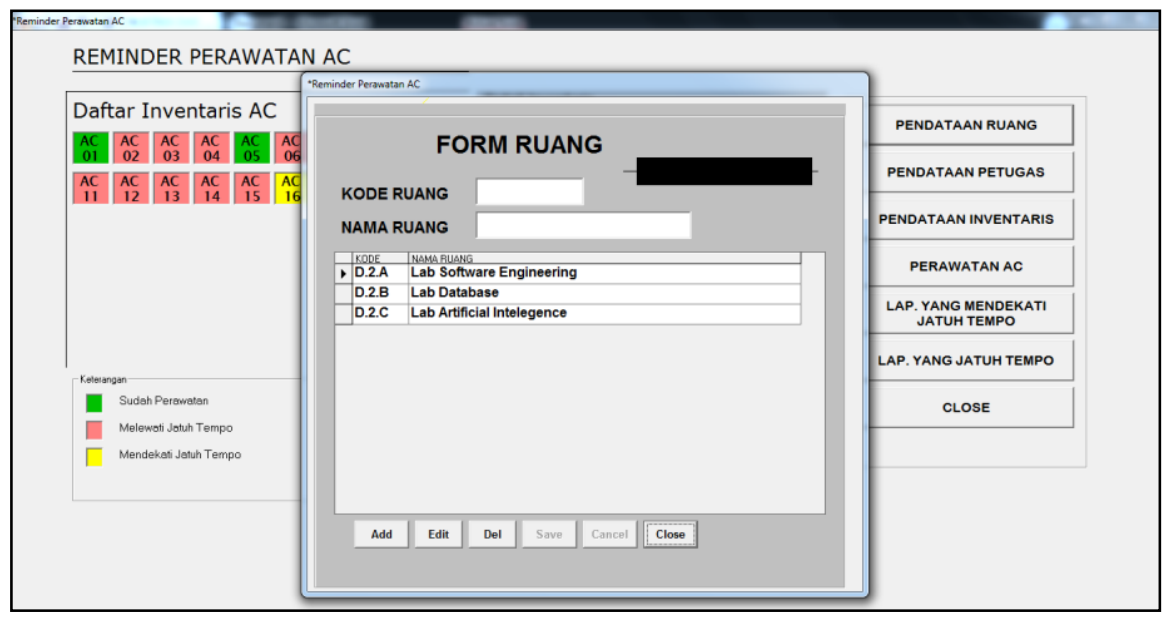

Gambar 4. Form pendataan ruang

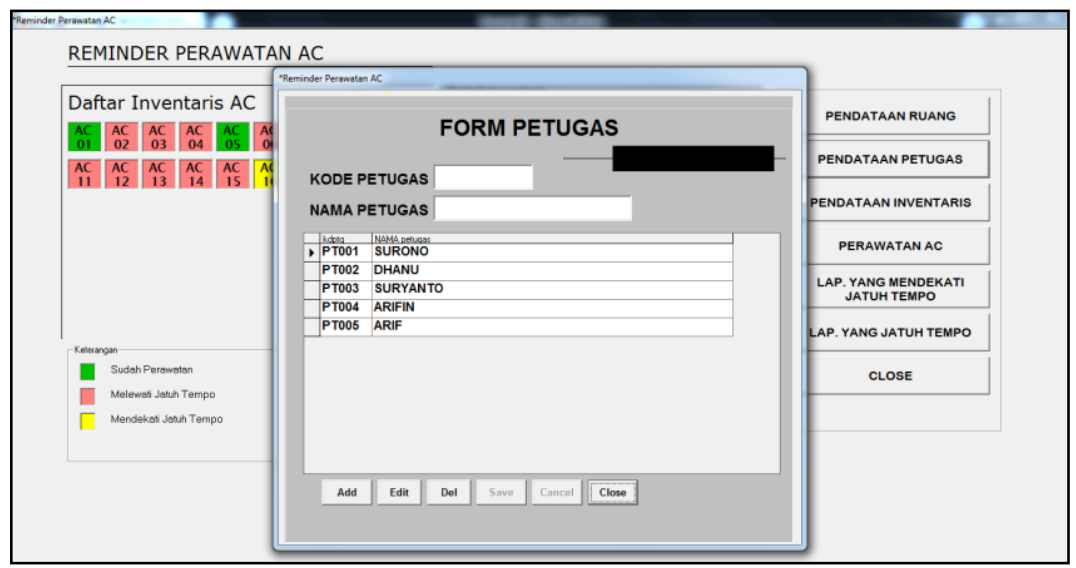

Gambar 5. Form pendataan petugas

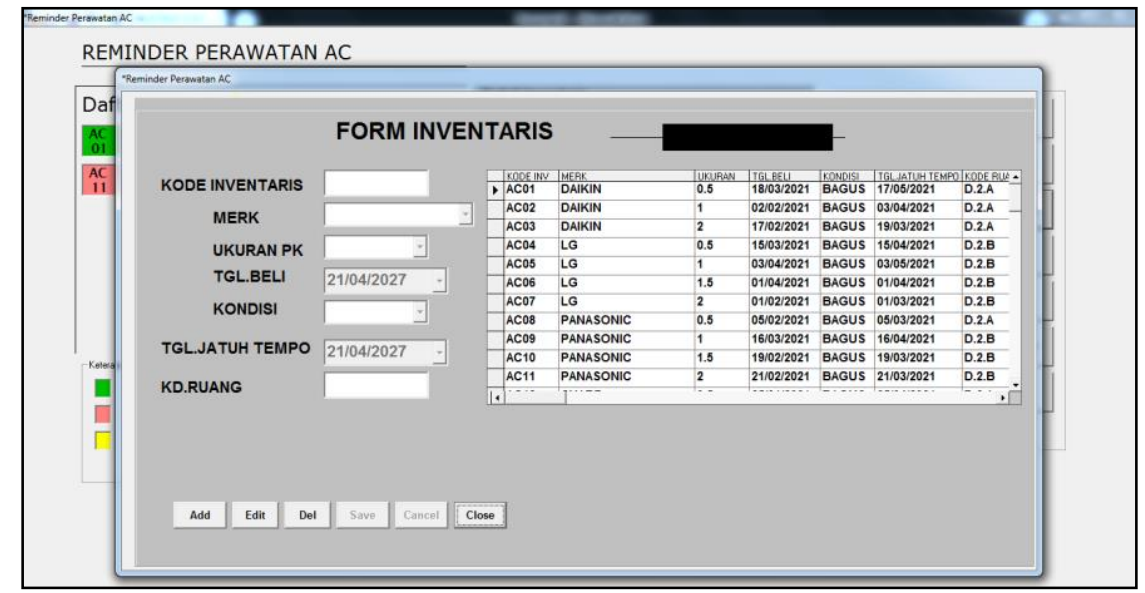

Gambar 6. Form Pendataan Inventaris 


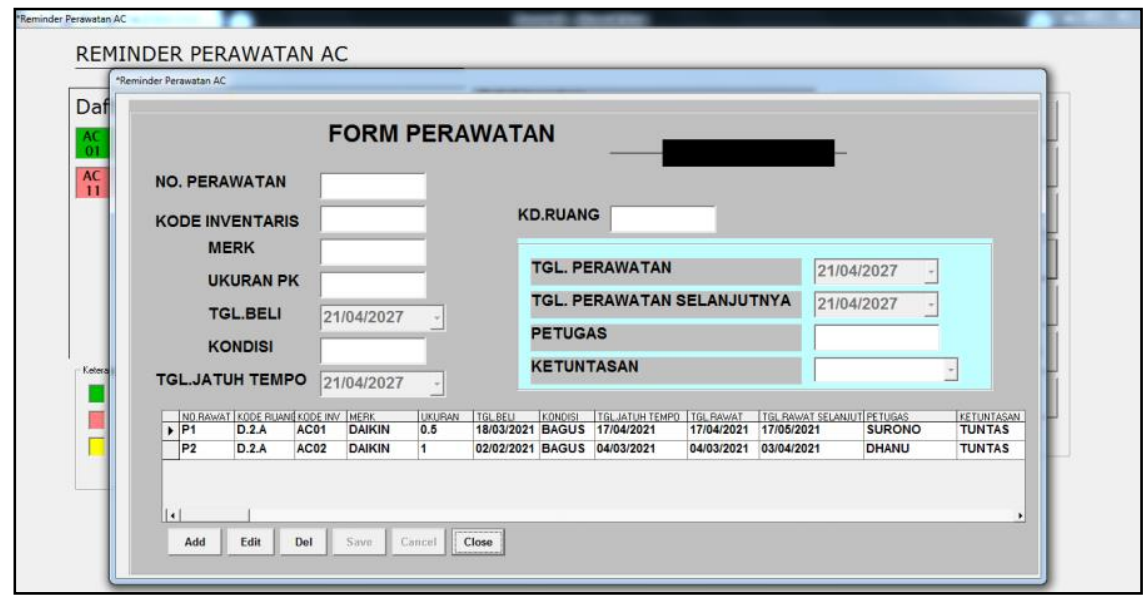

Gambar 7. Form Pendataan Perawatan

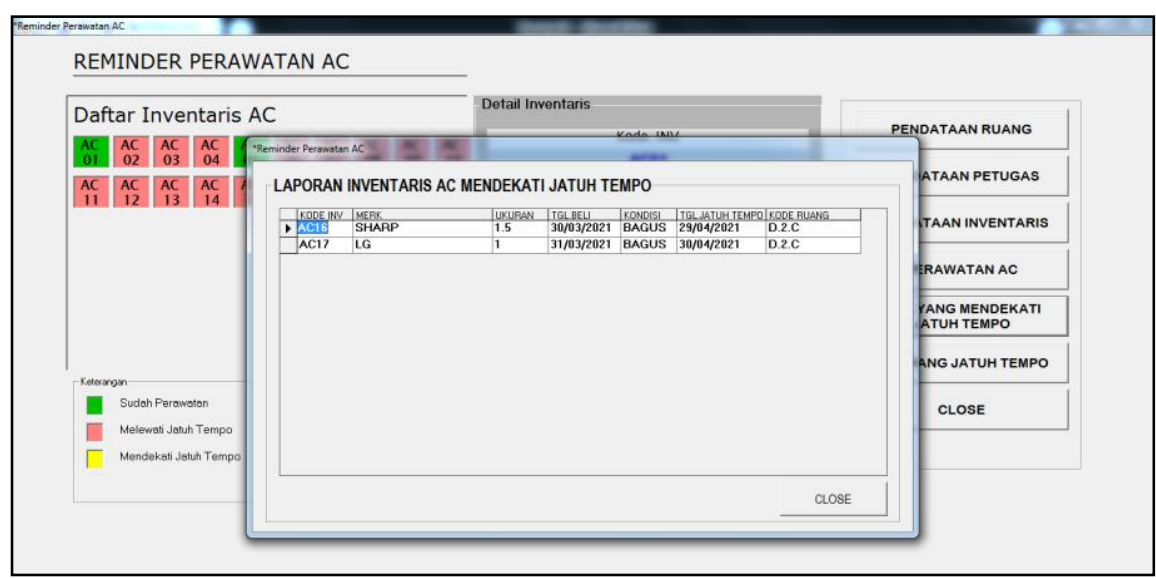

Gambar 8. Laporan Inventaris AC yang mendekati jatuh tempo

Pada gambar 10 adalah daftar inventaris AC yang mengalami perawatan, dan sudah melebihi tanggal jatuh tempo. Selain itu, terdapat kode, merek, tanggal beli, kondisi, dan kode ruang untuk mengetahui tempat atau lokasi AC tersebut berada.

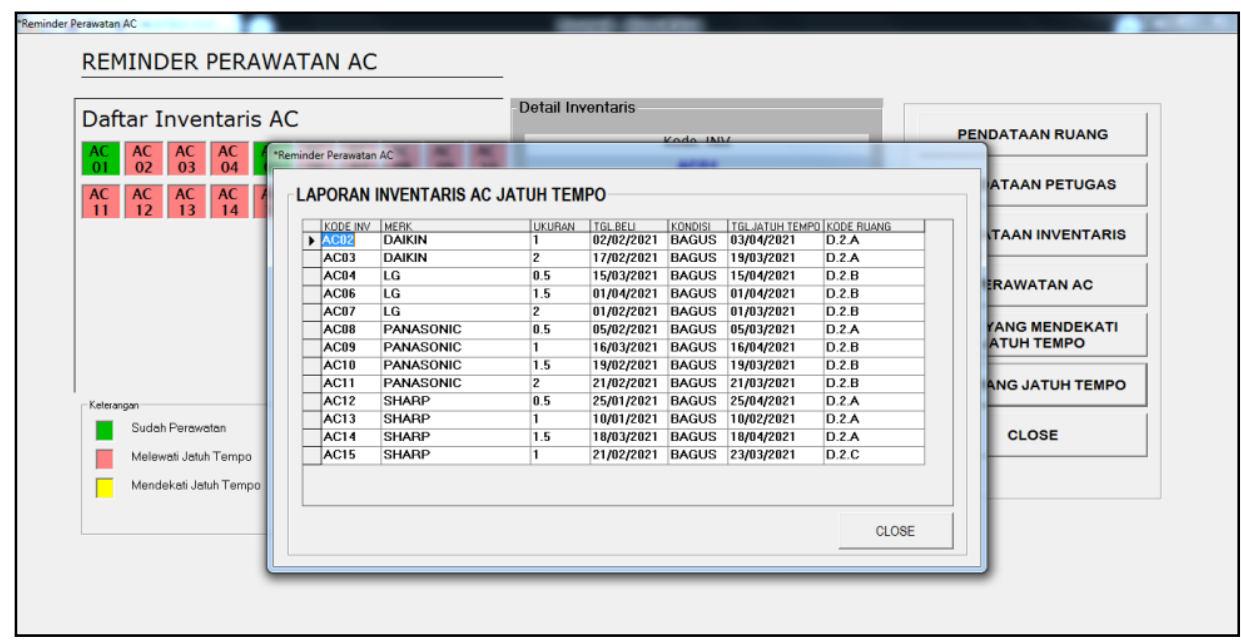

Gambar 9. Laporan Inventaris AC yang jatuh tempo

Testing atau pengujian dilakukan dengan blackbox, melalui pengujian langsung dengan menguji setiap bagian program apakah sudah memenuhi atau belum tanpa harus tanpa melihat struktur program(Rosalina, Rassi, Hadi, Ubaidillah, \& Desyani, 2020) . Pada sistem 
lama sistem pencatatan perawatan masih melalui kartu perawatan maupun buku perawatan sehingga belum mampu memberikan reminder perawatan AC, sedangkan sistem informasi tentang reminder AC memberikan kemudahan bagi pada petugas, mampu menjawab kesulitan yang dialami pada sistem lama yaitu sulitnya mengontrol waktu perawatan sehingga mengakibatkan kerusakan pada sejumlah AC. Hasil pengujian sistem kami menggunakan blackbox testing terlihat pada tabel 2 .

\section{Pembahasan}

Hasil temuan kami setelah dilakukan proses pembangunan sistem ini, hasil temuan kami adalah hasil analisis di lapangan menujukkan bahwa banyaknya kartu perawatan teknisi yang diisi sewaktu teknisi melakukan perawatan AC di setiap ruangan, Belum adanya pencatatan pada buku laporan perawatan, banyaknya AC yang belum di servis sampai dengan tanggal jatuh tempo perawatan, dan Jarang dilakukan perawatan pada AC, serta belum adanya laporan perawatan AC yang memuat semua AC yang sudah dilakukan perawatan ataupun belum. Berdasarkan hal ini, dibutuhkan sistem yang dapat memudahkan pengguna atau pekerja untuk mempermudah dalam melakukan perawatan AC, sehingga tidak terjadi kerusakan fatal pada AC tersebut.

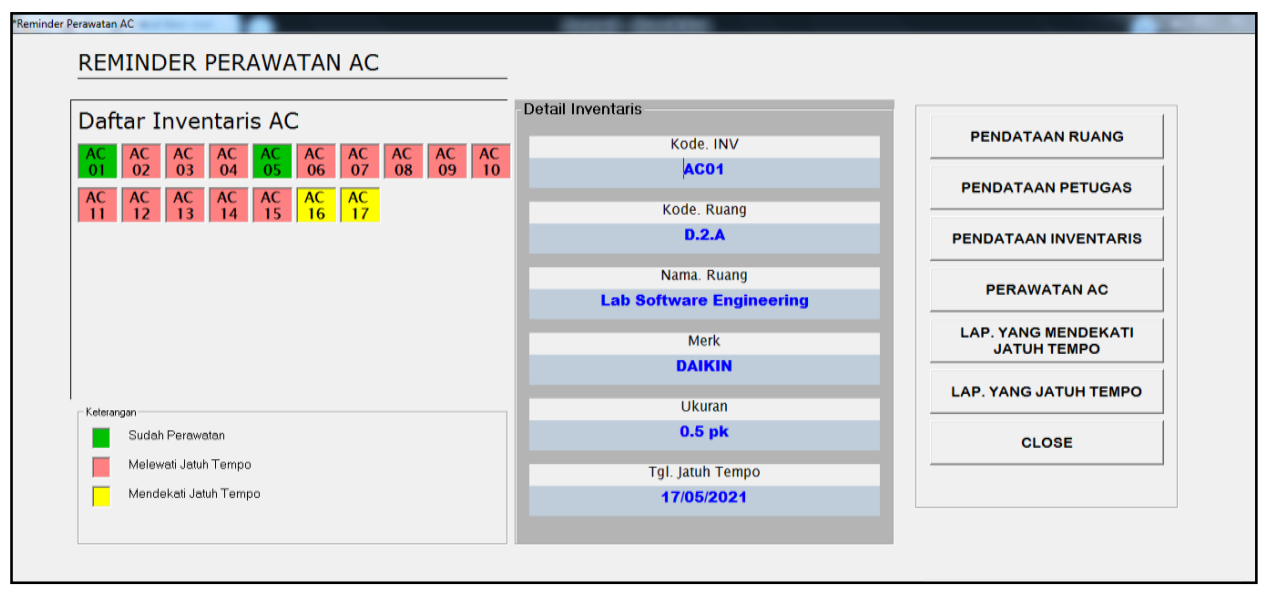

Gambar 10. Reminder Perawatan AC

Setelah dilakkan analisis, selanjutnya dilakukan desain sistem context diagram dan data flow diagram yang terlihat pada gambar 1 dan 2 . Pada context diagram tersebut, memberikan gambaran mengenai Teknisi memberikan dokumen daftar AC yang telah dilakukan perawatan ke sistem untuk selanjutnya teknisi menerima informasi berupa Reminder Daftar AC yang mendekati jatuh tempo perawatan AC dan Reminder Daftar AC yang melewati jatuh tempo perawatan AC. Entitas bagian sarana dan prasarana memberikan dokumen berupa dara ruang dan data inventaris AC. Entitas kepala teknisi menerima informasi berupa laporan jatuh tempo dan laporan mendekati jatuh tempo.

Selanjutnya context diagram diturunkan ke sub sistem dibawahnya yaitu data flow document seperti pada gambar 2. Pada Data Flow Diagram Level 0 sistem diperinci lagi menjadi sub sistem pendataan, sub sistem perawatan dan sub sistem cetak laporan. Dengan penyimpanan berupa tabel ruang, tabel inventaris dan tabel perawatan.

Pada sub sistem pendataan, entitas bagian sarana dan prasarana memberikan data ruang dan data inventaris AC ke sistem, untuk selanjutnya diolah dan diarsip ke tabel ruang dan tabel inventaris. Pada sub sistem perawatan, aktivitas perawatan diolah dari tabel inventaris dan tabel perawatan untuk kemudian dihasilkan Reminder Daftar AC yang mendekati jatuh tempo perawatan AC dan Reminder Daftar AC yang melewati jatuh tempo perawatan AC dari sistem guna diserahkan ke entitas teknisi. Pada sub sistem cetak laporan, aktivitas yang 
ada dengan mengambil data daeri tabel perawatan untuk selanjutnya dihasilkan laporan mendekati jatuh tempo dan laporan jatuh tempo.

Pada tahap implementasi, menghasilkan beberapa form atau menu pada sistem ini yaitu: pendataan ruang, petugas, inventaris, perawatan serta beberapa laporan. Pendataan ruang ini berfungsi untuk mendata atau mencari lokasi tempat adanya $\mathrm{AC}$, sehingga pengguna tidak perlu lagi mencari-cari rungan yang ber AC, karena datanya sudah ada. Pada form pendataan petugas adalah berfungsi untuk mencari siapa saja pegawai yang bertugas sesuai jadwal pada hari itu. Sedangkan form pendataan inventaris adalah sebuah form yang berfungsi untuk mendata semua data inventaris AC yang berapa pada setiap ruangan. Kolom inputan tanggal jatuh tempo nantinya berguna untuk mengecek pada aplikasi mengenai inventaris AC maana saja yang pada tanggal hari ini mendekati tanggal jatuh tempo. Pada form pendataan perawatan seperti pada gambar 7 adalah item tanggal perawatan selanjutnya muncul dengan rumus tanggal perawatan ditambah 30, yang mana tanggal perawatan selanjutnya nanti akan diset sebagai tanggal jatuh tempo. Form pendataan daftar inventaris AC yang sudah jatuh tempo dan mengalami perawatan, sehingga informasi yang diberikan oleh sistem ini dapat memantau pemakaian dari AC, dapat mencegah kerusakan yang fatal pada $\mathrm{AC}$ tersebut.

Tabel 2. Pengujian Blackbox

\begin{tabular}{|c|c|c|c|}
\hline Skenario & Testcase & Hasil Uji Coba & Kesimpulan \\
\hline $\begin{array}{l}\text { Tampilkan daftar } \\
\text { inventaris yang } \\
\text { sudah perawatan }\end{array}$ & $\begin{array}{c}\text { Inputkan data } \\
\text { perawatan inventaris } \\
\text { AC pada form } \\
\text { perawatan, masukkan } \\
\text { tanggal perawatan } \\
\text { Jika tanggal jatuh } \\
\text { tempo adalah lebih } \\
\text { seminggu (>7 hari) } \\
\text { dari tanggal hari ini } \\
\text { maka terpenuhi }\end{array}$ & $\begin{array}{c}\text { Muncul kotak } \\
\text { berwarna hijau pada } \\
\text { daftar inventaris AC }\end{array}$ & Memenuhi \\
\hline $\begin{array}{l}\text { Tampilkan daftar } \\
\text { inventaris yang } \\
\text { mendekati tanggal } \\
\text { jatuh tempo }\end{array}$ & $\begin{array}{c}\text { Inputkan data } \\
\text { perawatan inventaris } \\
\text { AC pada form } \\
\text { perawatan, masukkan } \\
\text { tanggal perawatan } \\
\text { Jika selesih tanggal } \\
\text { jatuh tempo dengan } \\
\text { tanggal hari ini } \\
\text { adalah }<7 \text { maka } \\
\text { terpenuhi }\end{array}$ & $\begin{array}{c}\text { Muncul kotak } \\
\text { berwarna kuning } \\
\text { pada daftar inventaris } \\
\text { AC }\end{array}$ & Memenuhi \\
\hline $\begin{array}{l}\text { Tampilkan daftar } \\
\text { inventaris yang } \\
\text { melewati tanggal } \\
\text { jatuh tempo }\end{array}$ & $\begin{array}{c}\text { Inputkan data } \\
\text { perawatan inventaris } \\
\text { AC pada form } \\
\text { perawatan, masukkan } \\
\text { tanggal perawatan } \\
\text { Jika selesih tanggal } \\
\text { jatuh tempo dengan } \\
\text { tanggal hari ini } \\
\text { adalah }<=0 \text { maka } \\
\text { terpenuhi }\end{array}$ & $\begin{array}{c}\text { Muncul kotak } \\
\text { berwarna merah pada } \\
\text { daftar inventaris AC }\end{array}$ & Memenuhi \\
\hline
\end{tabular}


Gambar 10 adalah informasi reminder atau peringantan yang muncul dan form ini berisikan mengenai kolom kode inventaris dengan warna hijau menunjukkan inventaris sudah mengalami perawatan, warna merah menujukkan inventaris AC sudah melebihi tanggal jatuh tempo dan warna kuning menunjukkan bahwa inventaris AC mendekati tanggal jatuh tempo. Informasi yang ditengah kode inventaris, kode ruang, nama ruang, merk, ukuran dan tanggal jatuh tempo akan muncul jika kotak yang berwarna tadi di klik.

Selanjutnya pada tahap testing dengan menggunakan blackbox, hasil temuan kami menunjukkan bahwa pada sistem lama sistem pencatatan perawatan masih melalui kartu perawatan maupun buku perawatan sehingga belum mampu memberikan reminder perawatan AC, sedangkan sistem informasi tentang reminder AC memberikan kemudahan bagi pada petugas, mampu menjawab kesulitan yang dialami pada sistem lama yaitu sulitnya mengontrol waktu perawatan sehingga mengakibatkan kerusakan pada sejumlah AC. Selain itu, berdasrakan hasil tersebut, semua komponen pada sistem sudah berjalan dengan lancar berdasarkan tujuan dan desain sebelumnya.

\section{SIMPULAN}

Berdasarkan hasil dan pembahsan, sistem yang baru akan memberikan kemudahan dalam mengontrol waktu perawatan serta mengetahui kondisi masing-masing AC dan petugas dengan mudah mengetahui tanggal jatuh tempo perawatan sehingga perawatan dapat dilakukan secara terjadwal serta akan berdampak pada umur inventaris AC yang optimal. Selain itu, system ini juga sudah sesuai dengan apa yang diharapkan berdasarkan hasil pengujian sistem menggunakan blackbox testing.

\section{REFERENSI}

Akbar, T., \& Gunawan, I. (2020). Prototype Sistem Monitoring Infus Berbasis IoT (Internet Of Things). Edumatic: Jurnal Pendidikan Informatika, 4(2), 155-163.

Anisah, A. (2019). Desain Sistem Informasi Administrasi Bimbingan Konseling pada SMA Negeri 1 Tempilang dengan Model Fast. Jurnal Sisfokom (Sistem Informasi Dan Komputer), 8(1), 92-97.

Fadhlurrahman, M. F. F., \& Capah, D. A. H. (2020). Aplikasi Penyewaan Lapangan Futsal Berbasis Web. Edumatic: Jurnal Pendidikan Informatika, 4(2), 30-39.

Gunawan, A. S., Setiawan, A., \& Legirian, F. (2017). Perancangan Maintenance Management Informastion System untuk Unit Pemadam Kebakaran (Studi Kasus: PERUSAHAAN X). Jurnal Nasional Teknologi Dan Sistem Informasi, 3(2), 219-224.

Hidayat, T., \& Muttaqin, M. (2018). Pengujian sistem informasi pendaftaran dan pembayaran wisuda online menggunakan black box testing dengan metode equivalence partitioning dan boundary value analysis. Jurnal Teknik Informatika UNIS, 6(1), 25-29.

Margono. (2016). Managemen Pemeliharaan dan Perawatan Mesin. Traksi, 4(1), 42-48. https://doi.org/https://doi.org/10.26714/traksi.4.1.2006.\%25p

Melikhova, E. V, Rogachev, A. F., \& Skiter, N. N. (2019). Information system and database for simulation of irrigated crop growing. In Ubiquitous Computing and the Internet of Things: Prerequisites for the Development of ICT (pp. 1185-1191). Springer.

Mishra, R., Chaulya, S. K., Prasad, G. M., Mandal, S. K., \& Banerjee, G. (2020). Design of a low cost, smart and stand-alone PV cold storage system using a domestic split air conditioner. Journal of Stored Products Research, 89, 101720.

Munthe, I. R., Rambe, B. H., Pane, R., Irmayani, D., \& Nasution, M. (2020). UML Modeling and Black Box Testing Methods in the School Payment Information System. Jurnal Mantik, 4(3), 1634-1640.

Muntohar, A. (2020). Sistem Informasi Data Klien Berbasis Java Pada Kantor Notaris dan PPAT Arif. Edumatic: Jurnal Pendidikan Informatika, 4(2), 58-67. 
https://doi.org/10.29408/edumatic.v4i2.2515

Nasution, A. B. (2019). Rancang Bangun Sistem Informasi Perawatan Mesin Produksi Keramik dan Granit pada PT. Juishin Indonesia. Jurnal Informatika Kaputama, 3(2), $60-65$.

Nere, M., \& Buani, D. C. P. (2018). Penerapan Metode Waterfall pada Sistem Informasi Jasa Laundry (SIJALY) JensChax Laundy Bekasi. Jurnal Techno Nusa Mandiri, 15(2), 6976.

Nugroho, A. (2019). Menperin Minta Panasonic Kebut Produksi 10 Juta Unit AC. Retrieved January 10, 2020, from Rakyat Merdeka website: https://rm.id/baca-berita/ekonomibisnis/14709/menperin-minta-panasonic-kebut-produksi-10-juta-unit-ac

Purnia, D. S., Rifai, A., \& Rahmatullah, S. (2019). Penerapan Metode Waterfall dalam Perancangan Sistem Informasi Aplikasi Bantuan Sosial Berbasis Android. Prosiding Semnastek, 1-7. Jakarta: Fakultas Teknik Universitas Muhammadiyah Jakarta.

Putra, G. M. P., \& Irawan, A. (2020). Analisis Pemeliharaan Preventif AC Package Pada Gerbong Kereta Penumpang K1 Di Depo 2 Gerbong Kereta Bandung. GEMA: Jurnal Gentiaras Manajemen Dan Akuntansi, 12(1), 48-59.

Ridwan, M., Muhammad, M., \& Ramadhani, S. (2018). Rancangan Sistem Informasi Manajemen Aset di PT. Sentral Tukang Indonesia. Jurnal CoreIT: Jurnal Hasil Penelitian Ilmu Komputer Dan Teknologi Informasi, 3(2), 47-58.

Rosalina, A., Rassi, A. A., Hadi, G. Y., Ubaidillah, R., \& Desyani, T. (2020). Pengujian Black Box pada Sistem Informasi Penjualan HI Shoe Store Menggunakan Teknik Equivalence Partitions. Jurnal Informatika Universitas Pamulang, 5(1), 26-29.

Rusdin, R., Santoso, P. B., \& Darmadi, D. B. (2018). Rekayasa Sistem Informasi Manajemen Perawatan Mesin Perkakas di Laboratorium Proses Manufaktur Jurusan Teknik Mesin Universitas Brawijaya. Rekayasa Mesin, 9(2), 109-118.

Sasmito, G. W. (2017). Penerapan Metode Waterfall Pada Desain Sistem Informasi Geografis Industri Kabupaten Tegal. Jurnal Informatika: Jurnal Pengembangan IT, 2(1), 6-12.

Sholeh, M., Gisfas, I., \& Fauzi, M. A. (2021). Black Box Testing on ukmbantul. com Page with Boundary Value Analysis and Equivalence Partitioning Methods. Journal of Physics: Conference Series, 1823(1), 12029. IOP Publishing.

Suryanto, D. (2020). Analisis Perawatan AC (Air Conditioner) Unit Split Duct Menggunakan Metode Failure Mode And Effect Analysis Fmea di Hotel Harris Yello. JITMI (Jurnal Ilmiah Teknik Dan Manajemen Industri), 3(1), 67-75.

Trivedi, S., Bhola, S., Talegaonkar, A., Gaur, P., \& Sharma, S. (2019). Predictive Maintenance of Air Conditioning Systems Using Supervised Machine Learning. 2019 20th International Conference on Intelligent System Application to Power Systems (ISAP), 1-6. IEEE.

Ye, Y. (2020). Research on University Personnel Management Information System Based on Database. Proceedings of the 5th International Conference on Distance Education and Learning, 63-66. https://doi.org/https://doi.org/10.1145/3402569.3409037

Yuliandra, B., \& Jaeba, K. A. (2017). Perancangan Sistem Informasi Perawatan Mesin Pada PT XYZ. Jurnal Rekayasa Sistem Industri, 6(1), 9-20. 